\title{
Association between climate variables and dengue incidence in Nakhon Si Thammarat Province, Thailand
}

\author{
Fatima Ibrahim Abdulsalam, ${ }^{1}$ Supabhorn Yimthiang, ${ }^{1}$ Aroon La-Up, ${ }^{1}$ Pakorn Ditthakit, ${ }^{2}$ \\ Pannee Cheewinsiriwat, ${ }^{3}$ Warit Jawjit ${ }^{1}$
}

${ }^{1}$ Environmental, Safety Technology and Health Program, School of Public Health, Walailak University, Nakhon Si Thammarat; ${ }^{2}$ School of Engineering and Technology, Walailak University, Thasala, Nakhon Si Thammarat; ${ }^{3}$ Department of Geography, Geography and Geoinformatics Research Unit, Faculty of Arts, Chulalongkorn University, Bangkok, Thailand

\begin{abstract}
The tropical climate of Thailand encourages very high mosquito densities in certain areas and is ideal for dengue transmission, especially in the southern region where the province Nakhon Si Thammarat is located. It has the longest dengue fever transmission duration that is affected by some important climate predictors, such as rainfall, number of rainy days, temperature and humidity. We aimed to explore the relationship between weather variables and dengue and to analyse transmission hotspots and coldspots at the district-level. Poisson probability distribution of the generalized linear model (GLM) was used to examine the association between the monthly weather variable data and the reported number of dengue cases from January 2002 to December 2018 and geographic information system (GIS) for dengue hotspot analysis. Results showed a significant association between the environmental variables and dengue incidence when comparing
\end{abstract}

Correspondence: Warit Jawjit, School of Public Health, Walailak University, 222 Thaiburi, Thasala, Nakhon Si Thammarat, 80161, Thailand. Tel.: +66897319552. E-mail: warit.ja@wu.ac.th

Key words: Dengue fever; hotspot; coldspot; spatial statistics; geographic information systems; Thailand.

Acknowledgements: a research grant from Walailak University financially supported the research with grant number CGS-RF-2020/09 from November 2018 to November 2021. The authors' gratitude goes to the College of Graduate Studies, Walailak University for financial support and $\mathrm{Mr}$ Sarayoot Nakrod at the School of Engineering and Engineering Resources, Walailak University, for technical support rendered throughout the study.

See online Supplementary material.

Received for publication: 2 May 2021.

Revision received: 11 September 2021.

Accepted for publication: 15 September 2021.

(C) Copyright: the Author(s), 2021

Licensee PAGEPress, Italy

Geospatial Health 2021; 16:1012

doi:10.4081/gh.2021.1012

This article is distributed under the terms of the Creative Commons Attribution Noncommercial License (CC BY-NC 4.0) which permits any noncommercial use, distribution, and reproduction in any medium, pro- the seasons. Temperature, sea-level pressure and wind speed had the highest coefficients, i.e. $\beta=0.17, \beta=-0.12$ and $\beta=-0.11$ $(\mathrm{P}<0.001)$, respectively. The risk of dengue incidence occurring during the rainy season was almost twice as high as that during monsoon. Statistically significant spatial clusters of dengue cases were observed all through the province in different years. Nabon was identified as a hotspot, while Pak Phanang was a coldspot for dengue fever incidence, explained by the fact that the former is a rubber-plantation hub, while the agricultural plains of the latter lend themselves to the practice of pisciculture combined with rice farming. This information is imminently important for planning apt sustainable control measures for dengue epidemics.

\section{Introduction}

The global emergence, resurgence and redistribution of infectious diseases are affected by the current warming climate (Pachauri et al., 2014), particularly those transmitted by insects. According to the World Health Organization (WHO), infectious diseases are often highly sensitive to climate variations (WHO, 2005; Tian et al., 2015). Climate change, especially with regard to temperature, precipitation patterns and extreme weather events, is known to affect the emergence, incidence and geographical distribution of vector-borne diseases (Githeko et al., 2000). Across the geographically diverse regions of Thailand, the El-Nino Southern Oscillation (ENSO), the natural weather phenomenon that occurs periodically, is an important driver of dengue incidence (Tipayamongkholgul et al., 2009) and can therefore be seen as an important predictor of this kind of epidemic (Xiao et al., 2018). To have an informed optimal public health response, there is a need to be able to predict the direction and extent of weather effects (Braks et al., 2014) and dengue haemorrhagic fever among other re-emerging arthropod-borne viral (arboviral) diseases of great public health importance has been shown to have spread across tropical and subtropical countries in the world. For example, about $75 \%$ of the global population exposed to dengue live in the Asia Pacific (WHO, 2011, 2012), and it is the leading cause of hospitalization and death in children in the population of the 1.3 billion at-risk individuals who live within the region (Gubler, 2002; WHO, 2011, 2014). Dengue epidemics continue to occur in the Southeast Asia region with a regular cycle of 3 to 5 years, with disease severity and the number of cases currently increasing, particularly in Thailand, Indonesia and Myanmar (Shepard et al., 2013).

The tropical climate of Thailand encourages very high mosquito densities and is ideal for the transmission of dengue fever. In southern Thailand, severe dengue is influenced by the 
mean temperature (Xu et al., 2019), number of rainy days, amount of rainfall and relative humidity (Wongkoon et al., 2016a). The distinctive climate (i.e. having hot and humid weather almost all year round) and terrain of Nakhon Si Thammarat province is ideal for dengue transmission. A report has shown that of all provinces in the south of Thailand, the Trang and Nakhon Si Thammarat provinces have the longest dengue transmission duration from June to September compared to Krabi, Phuket, Ranong, Chumphon, and Surat Thani provinces with a dengue transmission duration from June to August (Wongkoon et al., 2016a).

Currently, geographic information systems (GIS) are increasingly used in disease epidemiology to identify, assess and analyse possible risk factors with respect to climatic, demographic and socio-economic variables. In the modulation of disease dynamics, spatial analysis tools in GIS software are often used to address epidemiological problems especially in high-risk areas (Rotela et al., 2007; Mondini and Chiaravalloti-Neto, 2008; Wu et al., 2009; Jeefoo et al., 2011). To test and detect the spread and pattern of disease incidence, the methodology includes spatial autocorrelation analysis, cluster analysis and temporal analysis (Brownstein et al., 2002; Tsai et al., 2009). For public health surveillance and understanding the growing incidence of mosquito-borne infections, improved progression in GIS has led to discovery and focus on disease clusters (hotspots) as they illustrate the dynamics of disease spread (Yeshiwondim et al., 2009). Especially where disease surveillance and control need to be targeted, spatial, temporal and space-time clustering are useful in identifying high-risk areas and spatially and temporally (Si et al., 2008). In this study, we focused on the number of reported dengue cases per 100,000 population for each district. Hotspots are statistically significant clusters that can feature high and low values and we used the Getis-Ord Gi* tool as it considers clusters in the context of neighbouring clusters. High values may be of interest but not necessarily statistically significant. For a feature to be a statistically significant hotspot, it has to have a high value and be surrounded by other clusters with high values as well. The situation is the same for coldspots, but here we are talking about low values surrounded by areas with similarly low values. Getis-Ord Gi* is not designed to detect spatial outliers as it interprets significant values only; thus positive $\mathrm{Gi}^{*}$ indicates local clustering of high values (i.e. hotspots) and negative $\mathrm{Gi}^{*}$ indicates local clustering of low values (i.e. coldspots) as we exclusively focused on these features.

Environmental factors such as temperature, rainfall, humidity and pressure are often used in statistical and mathematical models to study the association and relationship between weather variables and dengue incidence (Stewart-Ibarra and Lowe, 2013; Wongkoon et al., 2016a; Xiao et al., 2018; Xu et al., 2019). However, in this study, we included additional weather factors, such as the number of rainy days, wind speed, evaporation, cloud cover, sea-level pressure and population numbers at the district level. In climate-health studies, modelling the relationships between environmental variables and diseases can be challenging due to their complex nonlinear interactions that require particular models; hence the use of the generalized linear model (GLM) Poisson distribution to detect the association of climate variables and dengue cases.

It is important to understand the evolving pattern and trend of dengue as it determines the success of prevention and control intervention measures. To comprehend the spatial distribution of dengue at the district level, a retrospective study was conducted in the Nakhon Si Thammarat province in Thailand from 2002 to 2018. The purpose of the present study is to observe the relation- ship of climate variables and dengue cases at the district level, and also to examine the spatial distribution of dengue cases and identify dengue hotspots and coldspots districts by using GIS tools and applying the spatial cluster analysis techniques such as Getis-Ord Gi*statistics.

\section{Materials and methods}

\section{Study area}

Nakhon Si Thammarat province is located in the south of Thailand which is distinctive in climate, terrain and resources. It has a total area of approximately $9,942.5 \mathrm{~km}^{2}$ (3838.8 sq. mi) and a population in 2019 of 1,560,433 (771,530 males and 788,903 females) according to the provincial office (City Population, 2019; Provincial Office, 2021), which corresponds to a population density of 157 inhabitants $/ \mathrm{km}^{2}$. The province is situated between latitude $8^{\circ} 25^{\prime} 7^{\prime \prime} \mathrm{N}$ and longitude $99^{\circ} 57^{\prime} 49^{\prime \prime} \mathrm{E}$ on the western shore of the Gulf of Thailand encircled (clockwise from the south) by the provinces of Songkhla, Phattalung, Trang, Krabi and Surat Thani (Figure 1).

Nakhon Si Thammarat province is divided into 23 districts, which are further divided into 165 sub-districts and 1429 villages. There are three distinct weather patterns in a year. The summer season lasts from mid-February to mid-May and is followed by a rainy season that ends in mid-October, while the monsoon period extends from November to January.

\section{Data collection}

This research was a quantitative retrospective study based on mathematical models and statistics for the analysis of the collected secondary numerical data, predict the probability of dengue incidence and show hotspot and coldspot districts of Nakhon $\mathrm{Si}$ Thammarat.

\section{Epidemiological data}

Monthly reported dengue fever cases from January 2002 to December 2018 of all 23 districts in Nakhon Si Thammarat were obtained from the R506 national disease surveillance report system put in place by the Bureau of Vector-Borne Diseases, Ministry of Public Health, Thailand (Bureau of Epidemiology, 2019). The R506 national surveillance system, which shares similarities with the Centres for Disease Control and Prevention (CDC) in the United States, obtains data from public hospitals and health centres and codes disease entries according to the $10^{\text {th }}$ issue of the International Classification of Disease Codes (ICD-10). Based on regulations by WHO (WHO, 1997), all identified dengue cases including clinical criteria are required to be reported to the surveillance system by public hospitals and clinics every week (Department of Disease Control, 2001). Dengue fever is defined as the presence of acute fever with at least two clinical symptoms, such as muscle pain, beck-eye pain, severe headache, high fever, positive tourniquet test, or a leukocyte count $<5000 / \mu \mathrm{L}$ (Ministry of Public Health, 2019). In addition to a combination of any of the above clinical symptoms, defined cases of dengue haemorrhagic fever have a $10-20 \%$ haematocrit elevation. Serology confirmation of all reported cases varies between 10 and 50\% (Ministry of Public Health, 2019). There is considerable uncertainty regarding the severity and duration of symptoms and that affects the degree to which patients seek medical attention; hence, self-reported data underestimates the real outcome of infectious diseases. 


\section{District population data}

Population data from each district of the province from the period of January 2002 to December 2018 were obtained from the Department of Provincial Administration with a registration statistics system database (Department Provincial Administration, 2019).

\section{Weather variables}

Monthly data from six weather stations in Nakhon Si Thammarat, Surat Thani, Koh Samui, Phat Thalung, Krabi and Trang from January 2002 to December 2018 were retrieved from the provincial Thai Meteorological Department (TMD) (Meteorological Department of Thailand, 2015). These include temperature, relative humidity, rainfall, number of rainy days, wind speed, evaporation, cloud cover and sea level pressure. The data however obtained, are subject to some degree of uncertainty as they are estimates of true values.

\section{GIS mapping}

By the use of GIS techniques in ArcGIS v. 10.8.1 software (ESRI, Redlands, CA, USA), the spatial distribution of dengue cases were mapped district-wise. Map data files were obtained from the office of the Department of Lands, Thailand Ministry of Interior Services, where it was codified and available for academic purposes at a scale of 1:1,000,000 (Thailand Interior Ministry, 2016). The information was stored based on geographical coordinates using the official geodetic reference system of Thailand for cartographic purposes, i.e. the Geographic Coordinate System GCS_WGS_1984 UTM_Zone_47N. It maps precise spatial relationships of different geographical objects employing simple geometry of points, lines and areas.

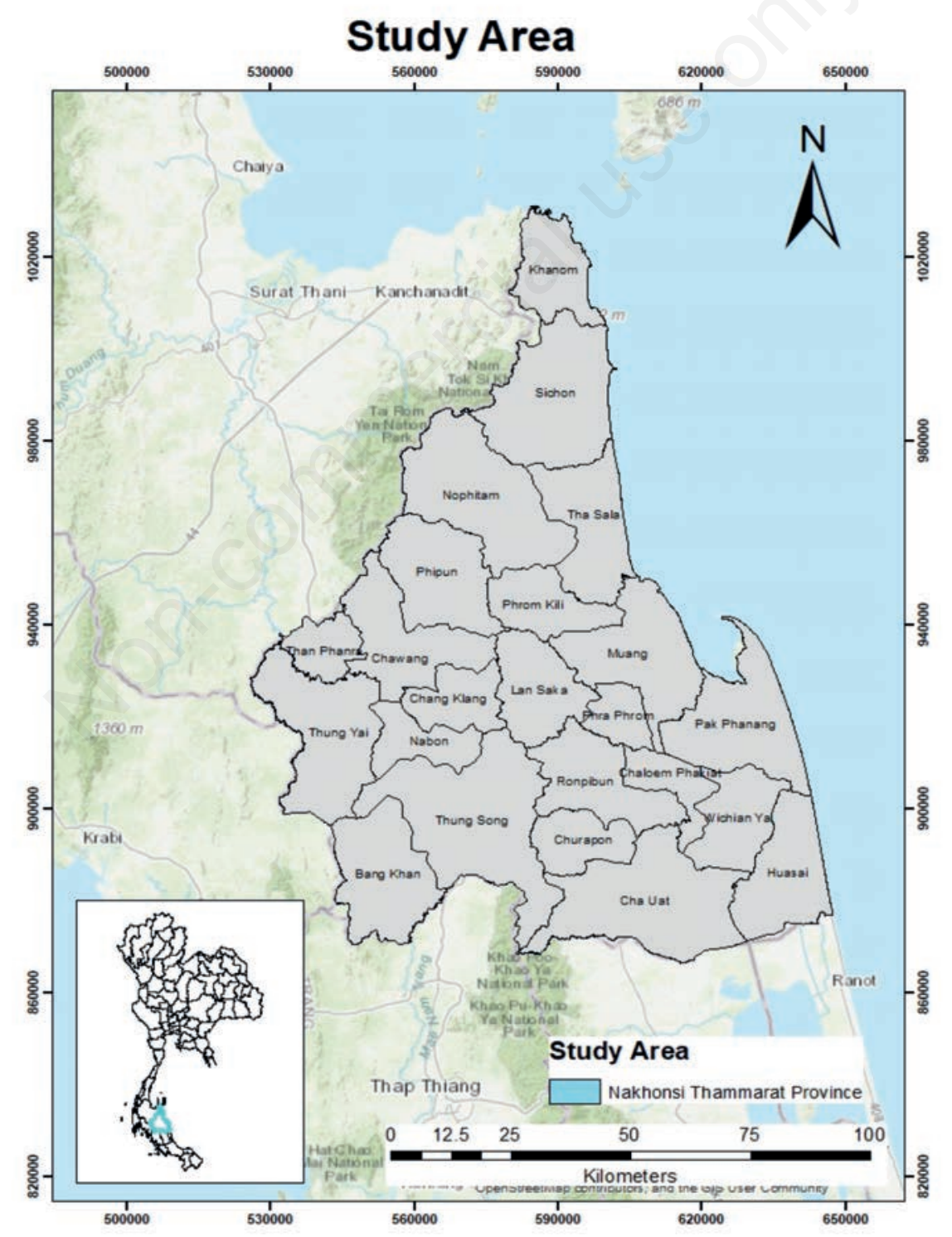

Figure 1. The study area covering all of Nakhon Si Thammarat Province with its 23 districts. 


\section{Data analysis}

\section{Temporal analysis}

The yearly reported dengue cases from January 2002 to December 2018 for each district, as well as their respective incidence rates were analysed. Temporal patterns were analysed and a classic Poisson regression between seasonal climate variables and dengue incidence rate was carried out.

\section{Predictive model}

A GLM was used in this study using the number of dengue cases as count data. GLM Poisson regression analysed associations between monthly reported dengue incidence (dependent variable) and environmental variables (independent variables like temperature, relative humidity, rainfall, number of rainy days, wind speed, evaporation, average cloud cover and average sea-level pressure) over 204 months between January 2002 and December 2018. GLM is suitable as it can include non-continuous variables, account for nonlinear relationships and handle non-Gaussian error distributions. The probability of the disease is based on the Poisson distribution (Lawless, 1987) calculated as:

$$
\mathrm{P}=\frac{e^{-l} \lambda^{y}}{y !}
$$

where, $\mathrm{P}$ is the probability of $y$ events occurring and $\lambda$ a constant, which is equal to the mean and the variance. The model to find the correlation is: $\ln ($ count $)=a+\beta_{1} x_{1}+\beta_{2} x_{2}+\ldots+\beta_{k} x_{k}$, where $a$ is a constant; $b$ is the coefficient of each $x$ (which is an independent variable).

\section{Spatial analysis}

\section{Hotspot detection}

By using spatial autocorrelation regression at the local level, different spatial cluster patterns like hotspots, coldspots, high-risk can be identified in a study area by the Getis-Ord Gi* statistics (Ord and Getis, 1995; Osei and Duker, 2008; Getis and Ord, 2010). Hence, this method was chosen to analyse dengue distribution patterns and to show groupings within the study area. With the confidence levels (CLs) set at 90\%, 95\% and 99\%, the output was calculated and given in form of Z-scores and P-values from Gi* statistics. The Z-score identifies spatial clustering of low values (coldspots) and high values (hotspots) through the Mapping Clusters tool in the Spatial Statistics Tools suite of ArcGIS (ESRI 2021) and is defined as:

$$
G_{i}^{*}=\frac{\sum_{j=1}^{n} w_{i, j} x_{j}-\bar{x} \sum_{j=1}^{n} w_{i, j}}{s \sqrt{\frac{n \sum_{j=1}^{n} w_{i, j}^{2}-\left(\sum_{j=1}^{n} w_{i, j}\right)^{2}}{n-1}}}
$$

where $G_{i}{ }^{*}$ is the Z-score; $x_{j}$ the attribute value for feature $j ; w_{i, j}$ the spatial weight features between the neighbourhood points $i$ and $j$; $n$ equal to the total number of features; with

$\bar{X}=\frac{\sum_{j=1}^{n} x_{j}}{n}$ as the mean of variable $x$ over all $j$ s; and
$S=\sqrt{\frac{\sum_{j=1}^{n} x_{j}^{2}}{n}-(\bar{X})^{2}}$ as the standard deviation of variable $x$ over all $j \mathrm{~s}$

The neighbourhood is the key element for groupings. It is important to note that from the point of view of dengue distribution, even though a spot reaches a high Gi* value and automatically becomes relevant, it may not be a statistically significant hotspot (as it may be an outlier). For a location to be regarded as a statistically significant hotspot, it must have a high $\mathrm{Gi}^{*}$ value and be surrounded by neighbours of high values as well (Getis and Ord 2010). In selecting a distance method for the conceptualization of spatial relationship, the inverse distance (which has the assumption that the farther away an element is, the smaller the impact it has) option was chosen as it shows clear transition areas (SánchezMartín et al., 2019). With the inverse distance option, the calculation method for the distance between neighbourhoods was chosen as the Euclidean distance, which defines the shortest possible distance between points $i$ and $j$ (straight line).

As evidence to enable apt sustainable decisions by policymakers, this study precisely identified the geographical location of hotspots and coldspots of reported dengue cases of spatial relationship within the districts of Nakhon Si Thammarat Province, Thailand.

\section{Results}

\section{Temporal analysis}

The largest dengue incidence events occur during the rainy season except in 2006, 2011, 2012 and 2013 where the largest incidence was reported in summer (for 2006, 2011 and 2013) and during the monsoon (for 2012). The total number of reported dengue cases in Nakhon Si Thammarat from 2002 to 2018 was 46,087. The highest recorded cases were in the Muang, Thungsong and Thasala districts with 9025,5629 and 3270 cases, respectively, while the districts with the least recorded cases were Khanom, Churaphon, and Tham Phanra with 934, 621, 502 cases respectively (Figure 2). The highest number of recorded cases were in the years 2002 and 2010 (6412 and 6045 cases, respectively), while the lowest occurring cases were in 2004 and 2006 (697 and 646 cases, respectively) (Figure 3). As for dengue incidence (i.e. the number of cases per 100,000 inhabitants) over the years, the top three districts were Nabon, Lan Saka and Phrom Khili, while the least three were Churaphon, Sichon and Pak Phanang districts (Supplementary file S1).

There seems to be a 2-3 year epidemic cycle in the number of recorded cases in each district as observed in our study (Figure 3). This was also the case at the national level. In the years 1997 and 1998, Thailand incidence rate of dengue cases was at its peak recording about 167.2 and 211.4 cases per 100,000 inhabitants, respectively. However, the recorded incidence rates in 1999 and 2000 declined to the corresponding values of about 40.3 and 30.2, which later rose to peak again in 2001 and 2002 to reach 225.4 and 168.

In all districts, the number of dengue cases increased from April to a peak in July and then declines in October (Figure 4). This means that every year, most cases occur from April to October in the study area, which can be vividly observed for the Thung Song and Muang districts. When computing the total dengue inci- 
dence over the whole province for the different seasons, it is obvious that the largest incidence was during the rainy season (midMay to mid-October) followed by the monsoon from November to January, while summer from mid-February to mid-May had the lowest incidence (Supplementary file S1).

During the study period, it was observed that across the districts the weather variables showed monthly average values ranging from $26.3^{\circ} \mathrm{C}$ to $28.3^{\circ} \mathrm{C}$ for temperature, $79.1 \%$ to $87.6 \%$ relative humidity, total monthly rainfall from $43 \mathrm{~mm}$ (in February) to $378 \mathrm{~mm}$ (in November), 5 to 21 rainy days, 1.1 to 1.8 knots wind speed $(1.334 \mathrm{~km} / \mathrm{h}), 78 \mathrm{~mm}$ to $136 \mathrm{~mm}$ pan evaporation, average cloud cover of 5 to 7.3 okta (Okta is a measurement unit of cloud amount. An okta represents a cloud amount of one eight or less but not zero) and average sea-level pressure of $1008.4 \mathrm{hPa}$ to 1011.4 $\mathrm{hPa}$. Relative humidity, rainfall, number of rainy days, and average cloud cover begins to increase from April (Figures 5-8).

\section{Poisson regression}

GLM Poisson analysis was used to investigate the association between climate variables and the occurrence of dengue cases in Nakhon Si Thammarat. From Table 1, the seasonal influence of climatic factors on dengue incidence over the period shows that all explanatory variables are significantly associated with the number of dengue cases, some more than others. The number of rainy days, windspeed and sea-level pressure were negatively associated with dengue cases, while the others were positively associated, e.g. tem-

\section{Dengue cases from 2002-2018}

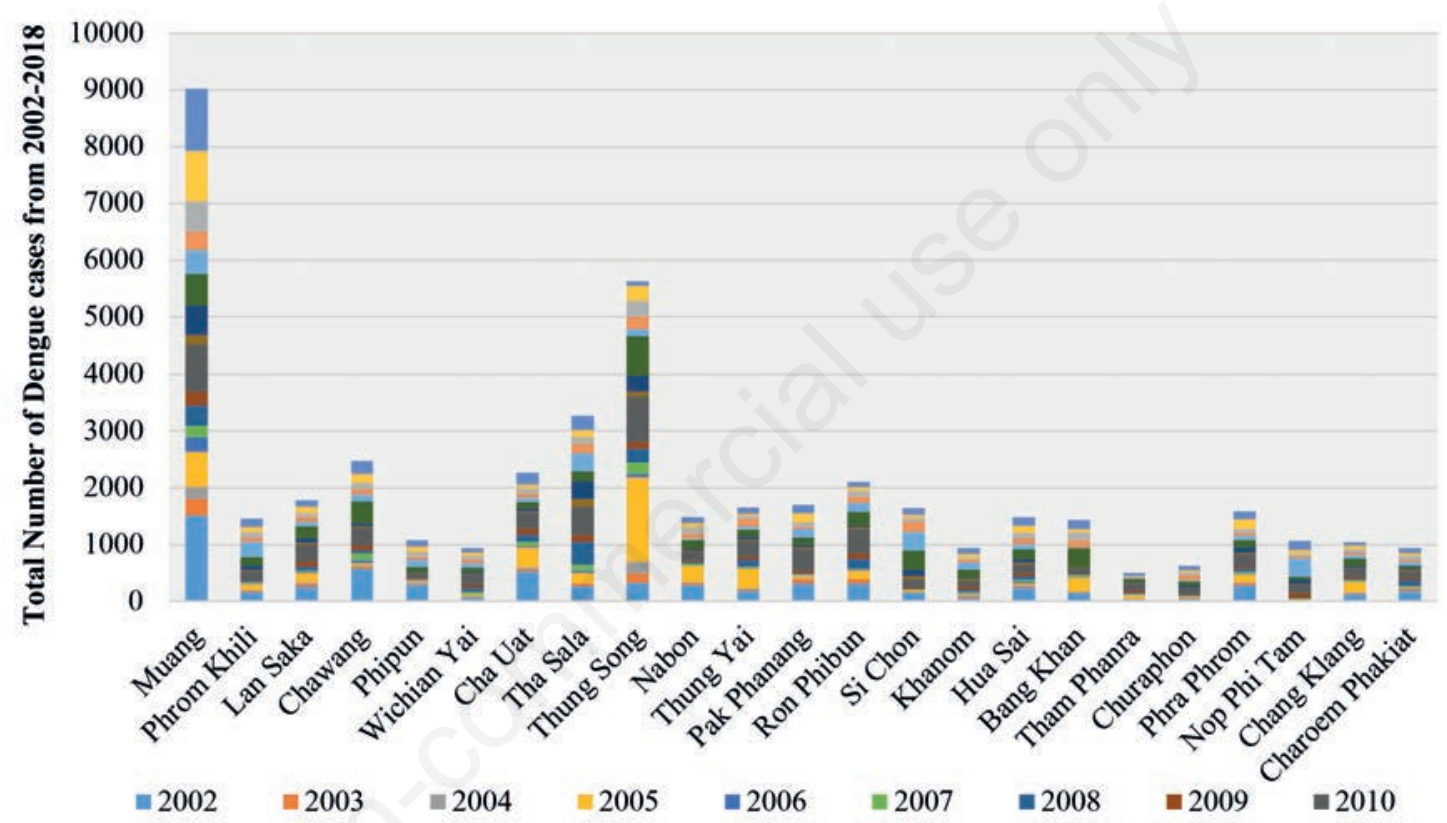

Figure 2. The number of dengue fever cases in all Nakhon Si Thammarat districts from 2002 to 2018.

Table 1. Correlation between variables, regressors and P-values.

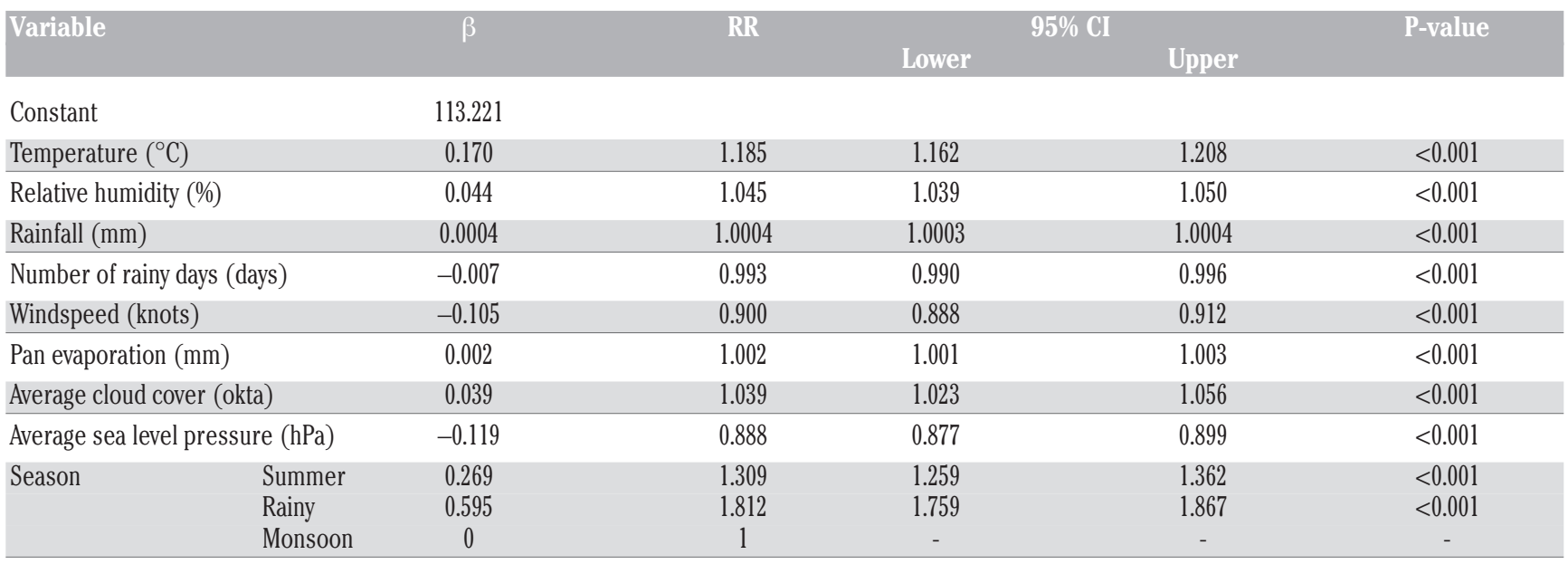

$\mathrm{RR}$, relative risk; $\mathrm{Cl}$, confidence interval. 
perature and sea-level pressure had the highest coefficient of $\beta=0.17$ and $\beta=-0.12(\mathrm{P}<0.005)$, respectively.

The regression equation suggests that on average every month (for about the past two decades), the dengue incidence changes by the corresponding $\beta$ coefficient for every unit change in the weather variable used. The climate variables temperature, windspeed and sea-level pressure seem to have the most effect on reported dengue cases in Nakhon Si Thammarat province; while those with the least effect are rainfall and pan evaporation. In addition, newly reported dengue cases are twice as likely to occur during the rainy season than monsoon.

The Poisson distribution regression model between dengue cases and seasonal climate variables can be written as:

(Dengue cases)

$=113.221+0.170$ (temperature) + (relative humidity)

+0.0004 (rainfall) -0.007 (number of rainy days) -0.105 (windspeed)

+0.002 (Pan evaporation ) +0.039 (average cloud cover)

- 0.119 (average sea -sea-level pressure) +0.269 (summer) +0.595 (rainy)

Compared to the monsoon season, the relative risk of dengue incidence was 1.8 and 1.3 times $(\beta=0.595, \beta=0.269)$ significantly higher during rainy and summer seasons, respectively. Also, according to our study, the relative humidity was observed to be

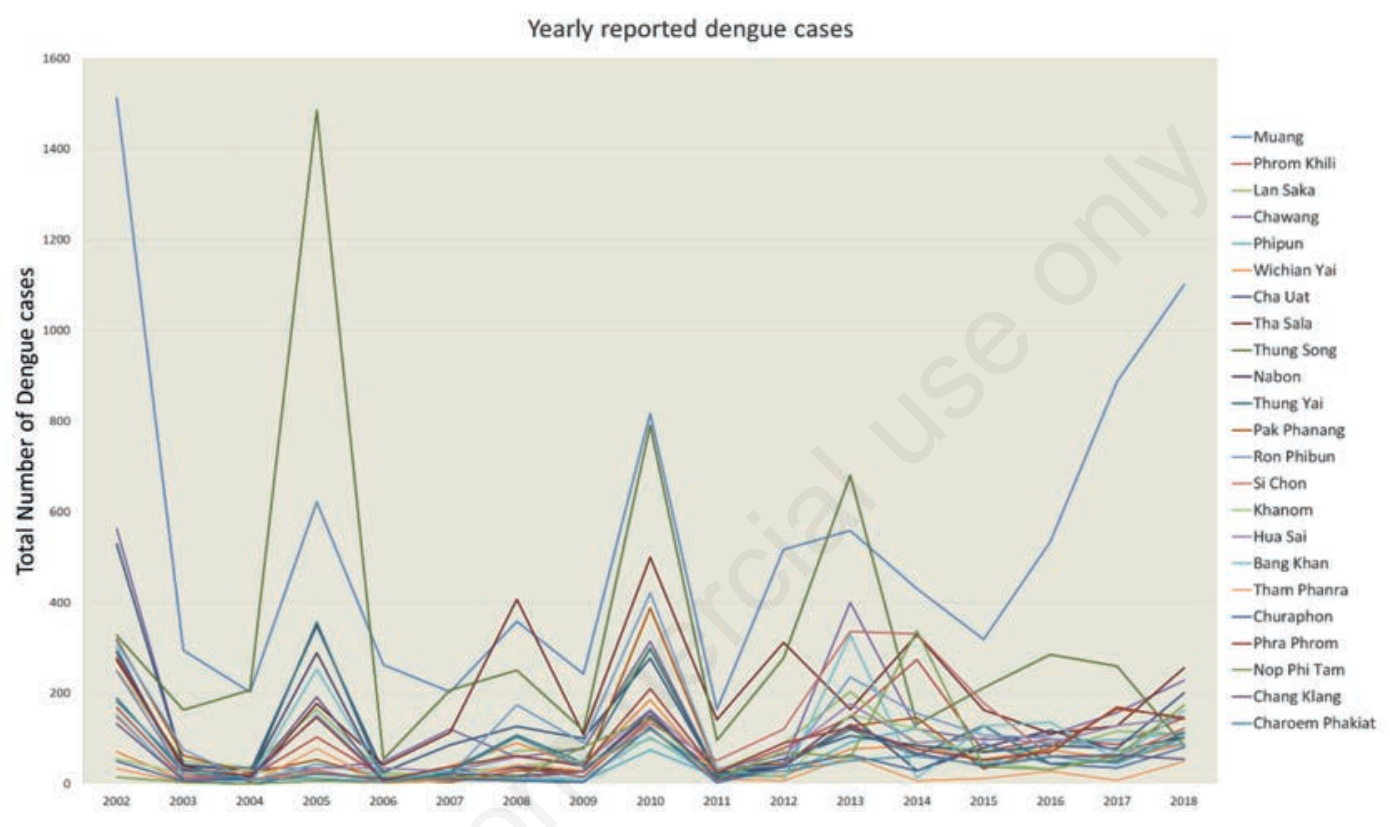

Figure 3. Yearly dengue cases according to each district in Nakhon Si Thammarat from 2002 to 2018.

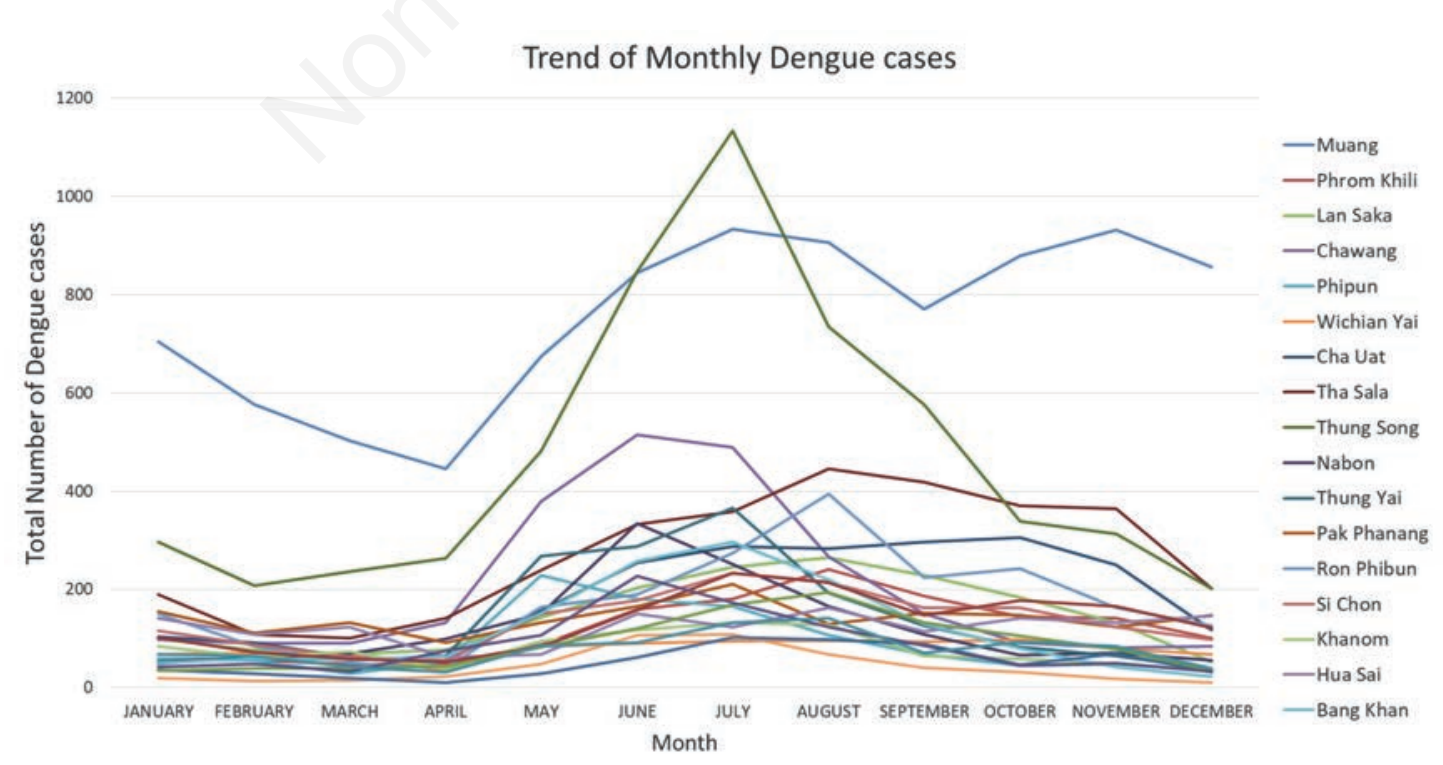

Figure 4. Monthly dengue cases according to each district in Nakhon Si Thammarat from 2002 to 2018. 

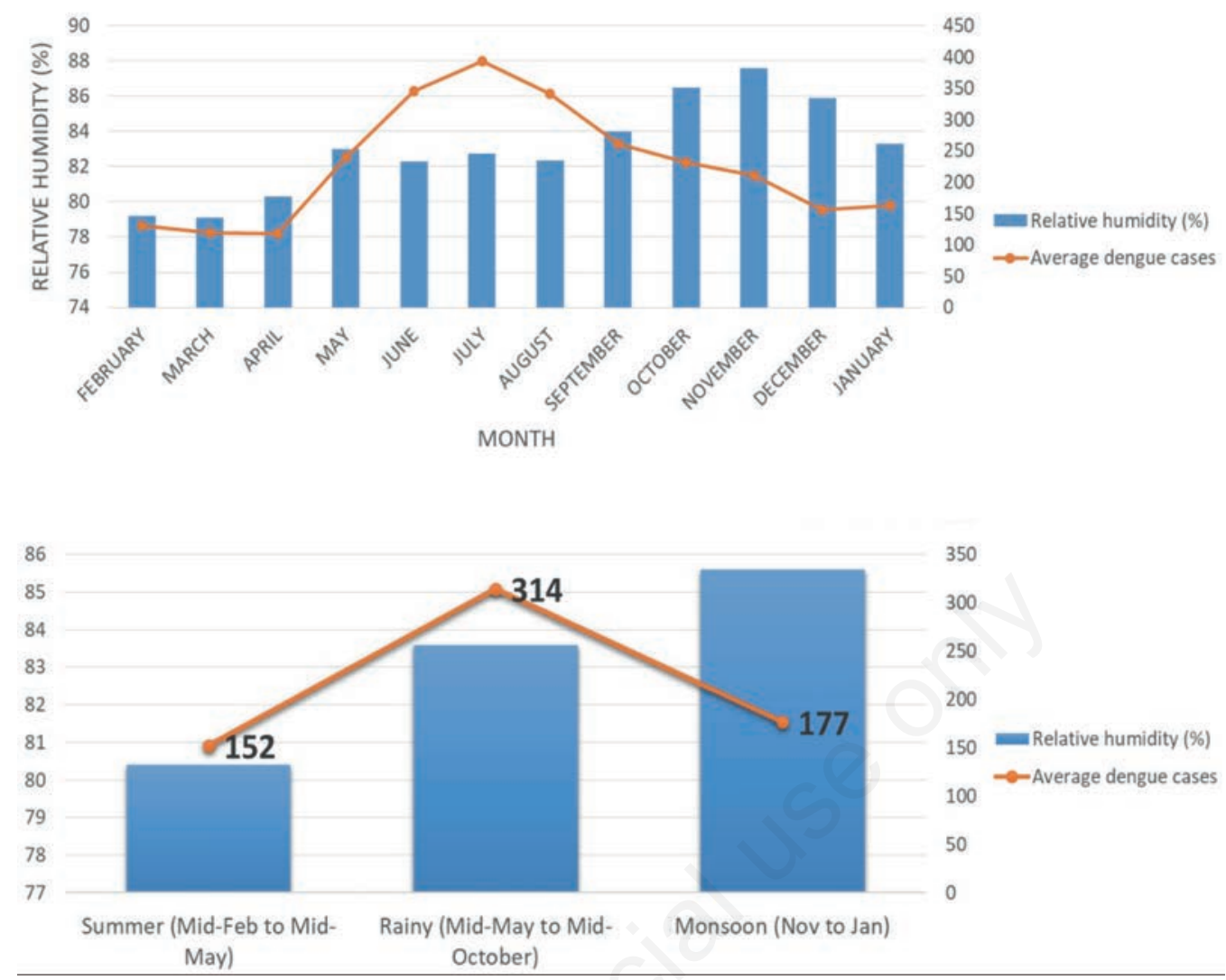

Figure 5. Average monthly and seasonal relative humidity in relation to number of dengue cases.
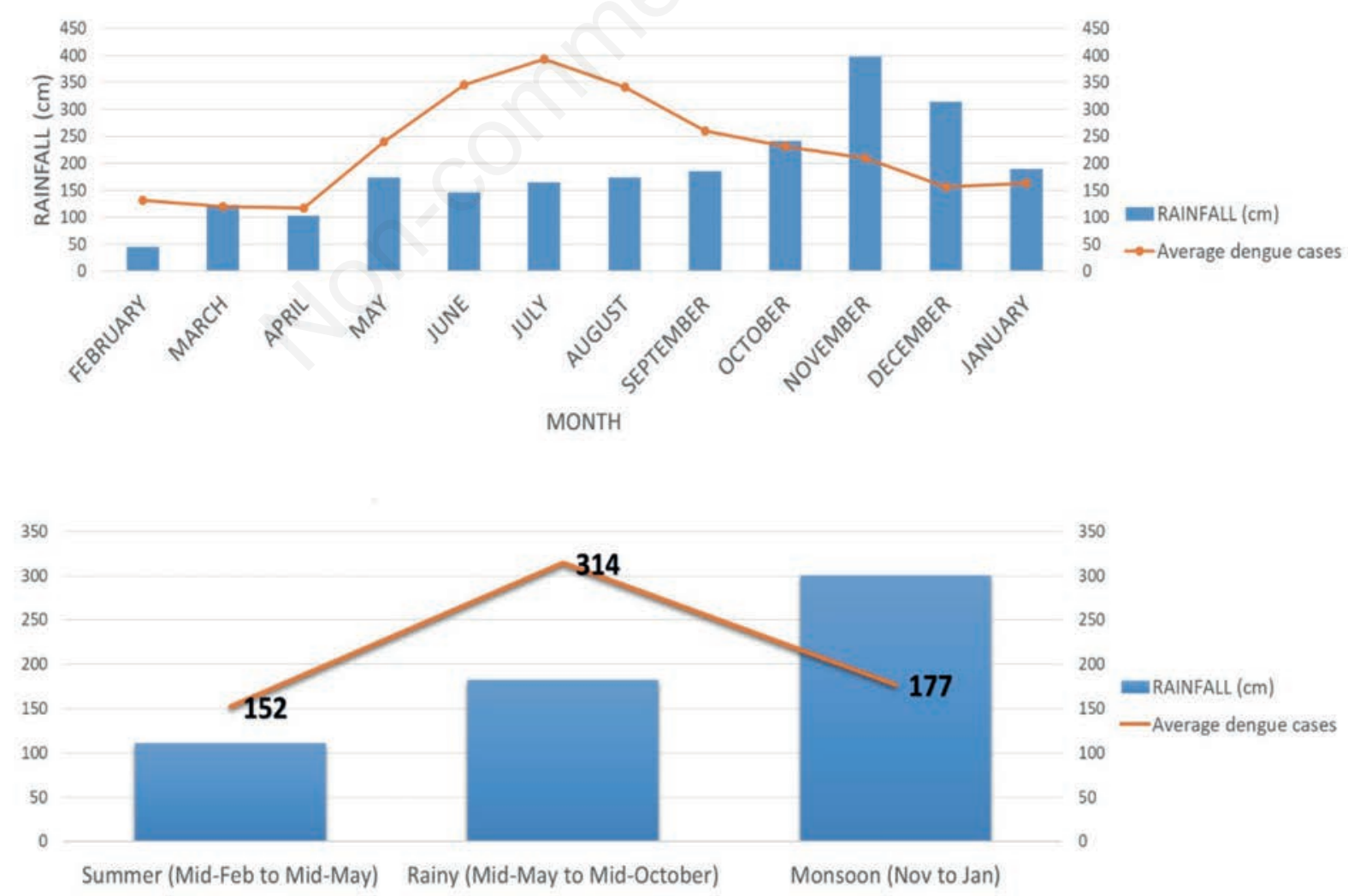

Figure 6. Average monthly and seasonal rainfall in relation to number of dengue cases. 

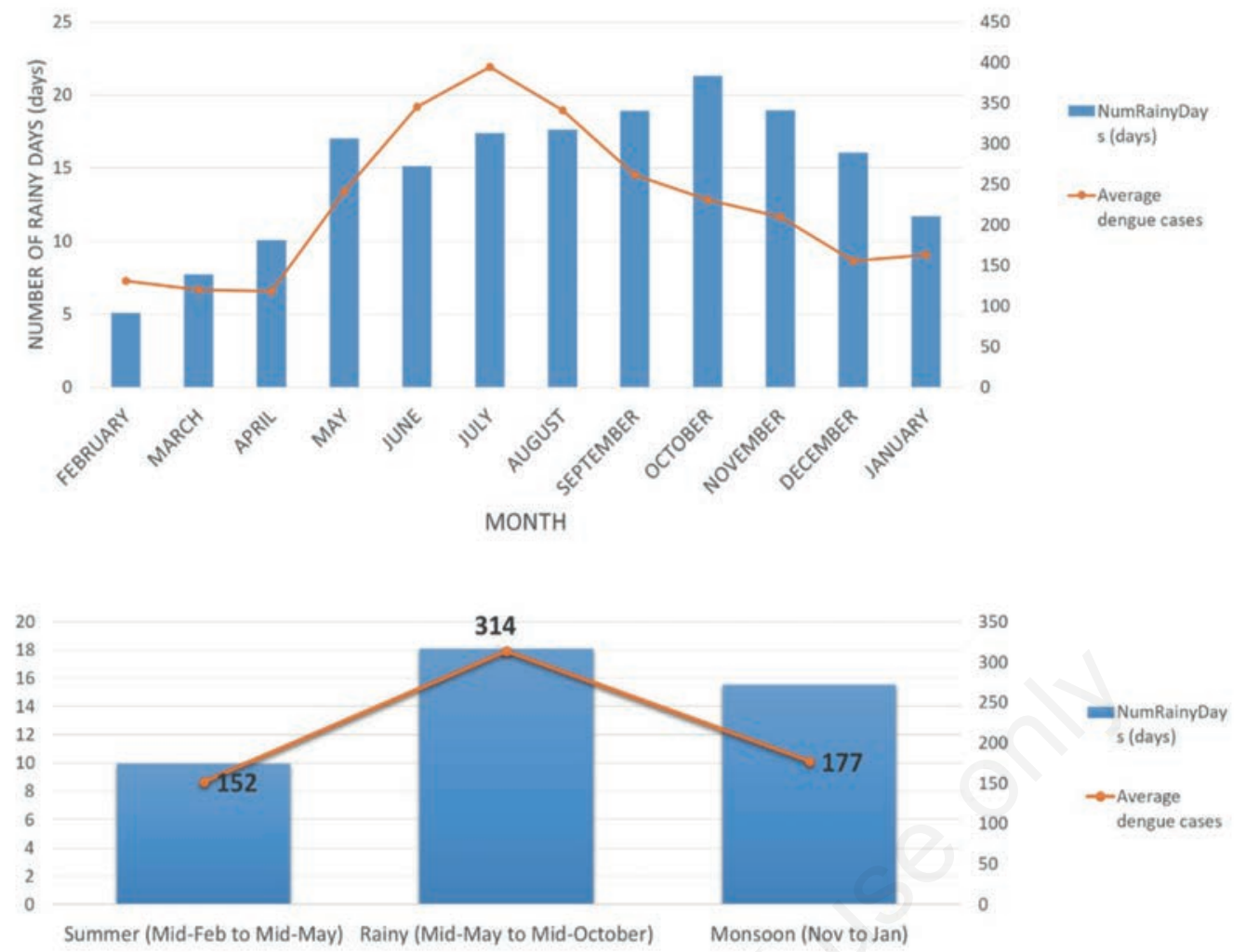

Figure 7. Average monthly and seasonal number of rainy days in relation to number of dengue cases.
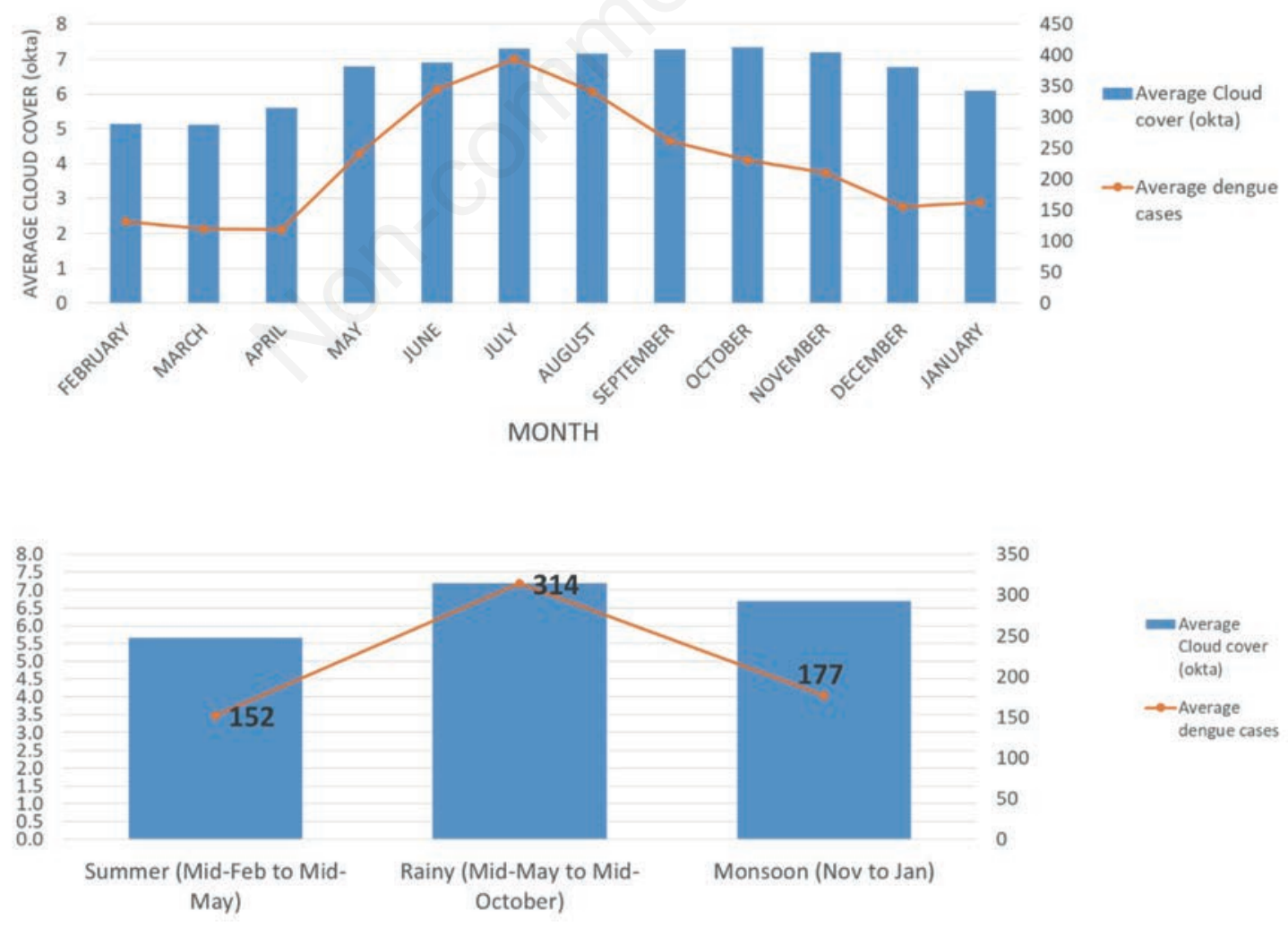

Figure 8. Average monthly and seasonal cloud cover in relation to number of dengue cases. 
highest during monsoon, which may have a negative effect on mosquito abundance. The temperature and pan evaporation, on the other hand, appeared to be the lowest during this time resulting in a significant positive effect on dengue incidence. Average sea-level pressure is negatively correlated to dengue incidence rate but significant enough to have an effect $(\mathrm{P}<0.01)$.

In our study, population influences dengue incidence as districts with the highest population such as Muang, Thasala, Phra Phrom, and Charoem Phakiat were shown to be dengue hotspots over the years (Figure 9).

\section{Hotspot analysis}

Results based on the Getis-Ord Gi* statistics (Figure 9) shows the yearly hotspot and coldspot analyses in Nakhon Si Thammarat province identifying the statistically significant spatial clusters of high and low values of dengue incidence from 2002 to 2018; as well as cumulatively during the study time period. Statistically significant spatial clusters of dengue cases were observed all through the province in different years. We noted negative Z-score values in the districts of Sichon (99\% CL in 2010), Pak Phanang (99\% CL in 2015) and Thungsong (95\% CL in 2018) showing that low values of the spatial distribution of dengue cases in the data set were more clustered than would be expected indicating coldspots. On the other hand, positive Z-score values in the districts of Nabon, Nophitam, Thasala and Lansaka (99\% CL); Thungsong, Muang and Chawang (both at 99 and 95\% CL observed across the years in Figure 9); Pipun, Bangkhan, Churaphon and Phra Phrom (99\% CL); and Charoem Phakiat, Khanom and Phromkili (95\% CL) show that the spatial distribution of high values of dengue cases were more clustered than would be expected indicating hotspots. In essence, we observed that the spatial clustering of high values of dengue cases was more pronounced than expected in a random distribution of dengue infection in Nakhon $\mathrm{Si}$ Thammarat as a whole.

\section{Discussion}

In different subtropical and tropical regions of the world, studies have been carried out on dengue and climatic factors; however, unlike those studies that mostly use temperature, rainfall and relative humidity as climate variables, this study includes other climate parameters like number of rainy days, wind speed, pan evaporation, cloud cover, sea-level pressure and population at the district level. It also provides useful information on dengue incidence trends and mapping patterns as it is imminently important to control dengue outbreaks by monitoring and planning sustainable control measures for epidemics.

Temporal analysis of climate factors has shown that in Nakhon Si Thammarat, the incidence of dengue infection spikes from the months of April to October, which is more than it was reported (from May to September) in the Chachoengsao province situated in the central region of Thailand (Jeefoo et al., 2011). Poisson correlation results of climate variables show a statistically significant result which is similar to a study conducted in Kuala Lumpur (Sulekan et al., 2021). According to Woongkoon et al., Nakhon Si Thammarat province has the longest dengue transmission duration

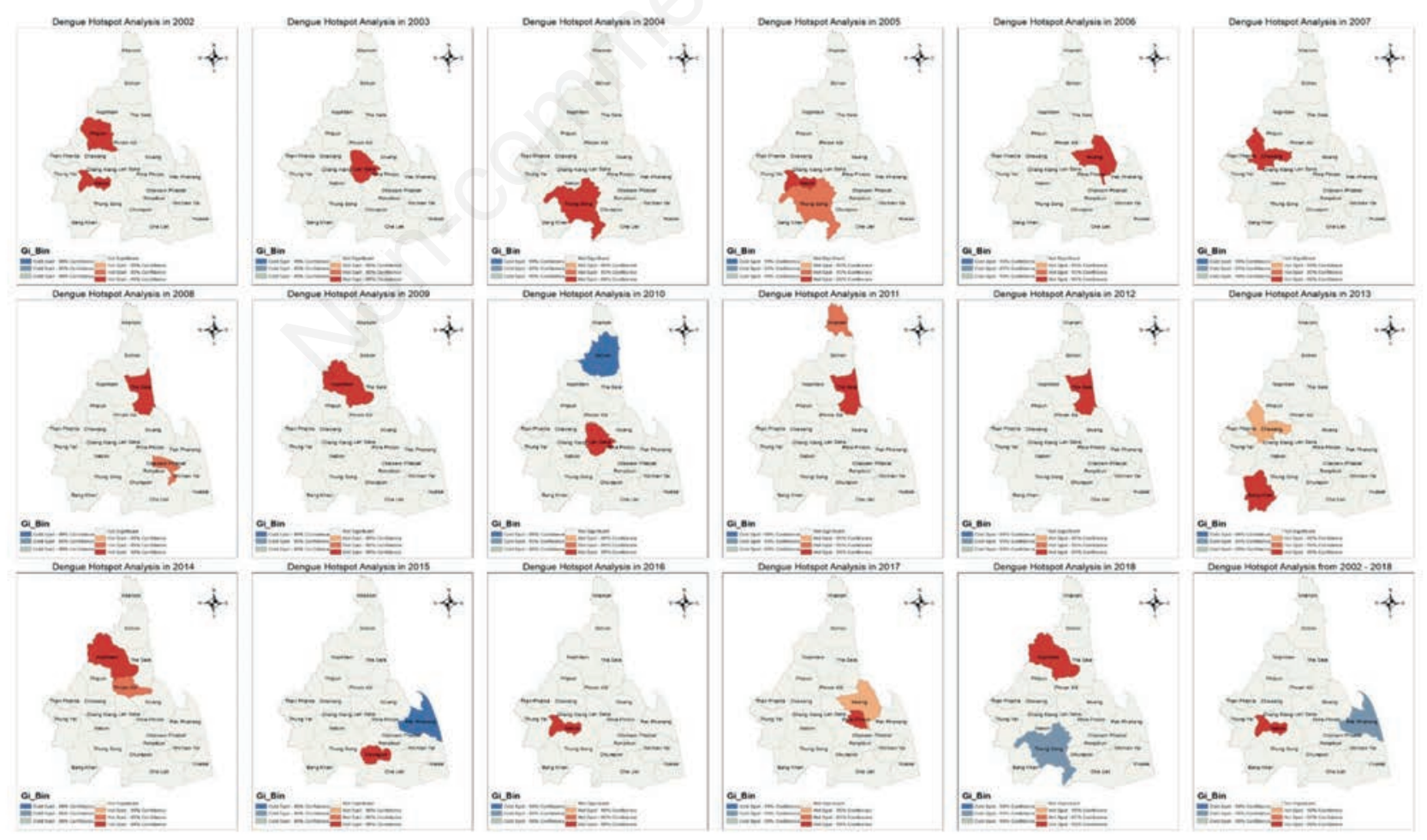

Figure 9. Map of Nakhon Si Thammarat Province showing the spatial clusters of dengue incidence from 2002 to 2018 by district. Hotspot and coldspot analyses based on Getis-Ord Gi* statistic. 
in the Gulf area of Thailand from June to September (Wongkoon et al., 2016a). The reported dengue cases, which are highest during rainy season, could be as a result of average cloud cover and number of rainy days being highest in the rainy season; as it is known that the larval stage of a mosquito vector is aquatic and so more rainy days increases vector population size and adult survival (Gubler et al., 2001) by the presence of artificial water bodies in discarded containers around the household. Both variables are equally suited to understand their relationship with dengue incidence as they show the highest correlations and are positive. Also, considering cloud cover in developing spatial and temporal models improves methods that investigate dengue epidemic changes (Tian et al., 2016).

Wind is known to have a dual effect that could either be positive or negative on mosquito vectors and their hosts. Wind speed results from our regression show a negative relationship with dengue incidence which was also found in other studies conducted in Vietnam, Barbados Sri Lanka and Malaysia (Depradine and Lovell, 2004; Cuong et al., 2011; Ehelepola et al., 2015; Sulekan et al., 2021). This shows that even though flight distance of mosquito may increase with wind thereby subsequently increasing human infection, strong winds do reduce mosquito density as well as biting opportunity making it difficult to find a host (Reid, 2000). Temperature significantly influences dengue infection. Due to the spatial-temporal distribution of mosquito-borne diseases affected by temperature, it is possible for the insects in low-latitude regions to find new habitats in mid- or high latitude regions and areas of high altitude as the temperature continues to rise, leading to geographical expansion or shift of diseases (Wu et al., 2016). Also, rainfall has been shown to significantly influence dengue incidence. Initially, rainfall is needed for mosquito larvae habitat, but incessant rainfall destroys these habitats, sweeping away the larvae. In Thailand, rainfall is strongly an influential weather factor in all provinces for dengue incidence (Chumpu et al., 2019).

Average sea-level pressure shows a significantly negative relationship to dengue cases in our study. A report by Tipayamongkholgul et al., suggests that sea-level pressure is a predictor of dengue epidemics in mountainous provinces of Thailand (Tipayamongkholgul et al., 2009) and it is reported that the salinity-tolerant mosquito vectors along the coasts are influenced by rising sea levels. Even though the predominant dengue vector (Ae. aegypti) in Thailand is a freshwater breeder, a rise in sea level could lead to its acclimation to breed in brackish or saline waters (Ramasamy and Surendran, 2011). According to literature, a limited short-term increase in salinity is tolerable to the Ae. aegypti larvae as it possesses the necessary physiological mechanisms resilient to such changes (Edwards, 1982). In vector control programs, brackish or saline water bodies are often neglected but advanced understanding in vector biology and relevant pathogen information could be crucial in developing effective counter control measures. In predicting the changing risk for infectious diseases caused by climate change, it is important to recognise that socioeconomic factors play a role. Here, population influences dengue incidence, and the top three densely populated districts are Muang, Thasala and Phra Phrom. Muang and Phra Phrom districts are in the top ten districts with the highest incidence rates and looking at Figure 1, these districts are adjoining. Muang is the administrative capital of the province so perhaps the movement patterns of people and spatial heterogeneity of human activities could encourage dengue transmission. One could say that dengue cases in surrounding districts could influence the number of dengue cases in a particular district.

To superimpose the temporal and spatial distributions of dengue cases, GIS is a powerful tool that can be used based on its application of ecological determinants like climate, landscape ecology, vector population, human presence and activity. Spatial distribution of dengue through cluster analysis and epidemiological scenarios was investigated in all 23 districts of the province. Looking at the hotspot analysis map from 2002 to 2018 Figure 9, Nabon is observed as a hotspot for dengue infection while Pak phanang is a coldspot. Statistically significant spatial clusters of dengue cases were observed all through the province in different years. This random distribution means that dengue infection in the province is not restricted to a particular region but that any district could be at risk of epidemic regardless of the year. Needless to say that population density is an important factor for dengue transmission, both Aedes mosquito vectors are adapted to the urban and peri-urban environment extremely well so much so that dengue is today a largely urban problem. While the Aedes aegypti mosquito lives in proximity to human habitations breeding mostly in manmade containers; Aedes albopictus populations are known to be more stable and established in areas with open spaces and vegetation better acclimated to cooler climates spreading the infection.

The topography of the study area is mountainous in nature (Provincial Office, 2021). The central mountain range include districts Thasala, Lansaka, Phrom kili and Muang which has shown a trend of being a dengue hotspot district over the years (Figure 9). Due to a changing climate, dengue fever cases are rapidly increasing in mountainous areas. The increase in potential duration of epidemic transmission season by some model projections have pictured a potential increase in altitude and latitude range of dengue mosquito vectors (Jetten and Focks, 1997), this could explain how across the study years, these districts have shown unexpected spikes of spatial clusters of high values consistently marking them as hotspot areas. Pak phanang district was observed to be a coldspot district, perhaps this could be because it is predominantly a rice-producing region including neighbouring districts like Huasai, Wichian Yai, and Cha uat, where the rice farmers practice fish culture in rice paddies. Mosquito-eating fish are introduced to the rice paddies to reduce vector population. Agricultural communities in southern India that practice pisciculture in their paddy fields observed $81 \%$ reduction of Anopheline population; so also in China where mosquito population decreased by $90 \%$ providing the farmers a net profit 2.5 times more than rice paddies where only rice was cultured (Wu et al., 1991; Victor et al., 1994). This has shown that successfully promoting pisciculture in rice farming is not only an effective strategy in mosquito vector control, it also is economically beneficial in attracting farming communities to participate in reducing dengue transmission.

The hilly western plains situated between the mountains of the study province include hotspot districts like Nophitam, Pipun, Chawang, Nabon, Thunsong and Bangkhan also shows the random spatial distribution of high-value clusters (Figure 9). The Nabon district which is seen to be the top hotspot over time is known to be the rubber plantation hub of the entire province. In rubber plantations, tree holes, latex-collection cups and water-storage containers around the homes of rubber-plantation workers are potential breeding sites for the Aedes mosquito (Thammapalo et al., 2011; Paily et al., 2013); exposing those living within the vicinity to daybiting mosquitoes. A study in Thailand suggests that townhouses have 18.3 times lesser odds of having at least a container with Aedes larvae when compared to rubber plantation houses 
(Thammapalo et al., 2005). In latex-collection cups containing rainwater, Aedes albopictus lay their eggs producing adult mosquitoes during rainy seasons. Unlike Africa, in Southeast Asia, rubber-plantation workers tap latex at night when the yield is highest making them exposed to mosquito bites; hence, it is safe to say that rubber plantation risks of mosquito-borne disease transmission depend on the daily activities of workers and seasonality of their work (Tangena et al., 2016).

According to Clark et al. (2005), the economic burden of dengue fever in terms of financial loss per family is higher than the average monthly income. To reduce the risk of dengue in Nakhon Si Thammarat, identifying appropriate and sustainable vector control measures by investing in the health of those living in dengue hotspots like Nabon district is likely to be financially beneficial especially to the economy of the rubber industry of South-East Asia by preventing worker absenteeism and lower productivity. This means that vector control measures should include interventions targeting both indoor and outdoor protection against biting mosquitoes involving collaboration from within and outside the health sector. Using both non-insecticide and insecticide-based control measures, the health/education sector, agricultural industry and local communities need to work hand-in-hand in choosing sustainable implementation strategies supported by climate, entomological and epidemiological surveillance. Alongside vector control measures, other strategies like improved health communication, access to health services for prompt and effective diagnosis and treatment, migrant community volunteer training and interaction with health workers should be explored. These approaches are in line with the WHO-recommended adaptive strategies for integrated vector management (IVM). Here, this study provides some prevention conducts for possible dengue hotspots at the district level.

The 2-3 year epidemic cycle in the number of recorded dengue cases in each district as observed in our study (Figure 3) was similar to the situation at the national level. In the years 1997 and 1998, Thailand incidence rate of dengue cases was at its peak recording about 167.2 and 211.4 cases per 100,000 inhabitants, respectively. However, the recorded incidence rates in 1999 and 2000 declined to the corresponding values of about 40.3 and 30.2, which later rose to a peak again in 2001 and 2002 to reach 225.4 and 168 (Thailand Health Ministry, 2001; Ongart Charoensuk et al., 2017). These changes could explain the high number of cases in 2002 found in our study.

The low incidence for the year 2011 was possibly due to the unexpected heavy rainfall that year. Rainfall is known to be a main driver of dengue transmission; however, in excessive amounts, it disrupts the mosquito vector life cycle flushing out the aquatic phase from breeding sites. A study comparing weeks with no flushing events to weeks with five or more flushing events found that the risk of a dengue outbreak was significantly reduced by up to $70 \%$ (Benedum et al., 2018). Recently, the dengue incidence rate has almost doubled from an average of 38.6 per 100,000 in 2018 to 67.6 in 2019, with the south of Thailand having a rate of 69.4 per 100,000 as of June 2019 (Thaivbd, 2019).

As shown in Figures 5-8, the relative humidity, rainfall, number of rainy days, and average cloud cover begins to increase from April. This timing translates into dengue outbreaks in the months of June, July and November as we report. Studies suggest that generally, dengue outbreaks happen when humidity is higher than average just as the rainy season begins (Guha-Sapir and Schimmer 2005) as adult mosquitoes tend to survive longer in increased humidity. Also during these months in our study, temperature, pan evaporation and sea-level pressure (in May, June and November) decreases (Supplementary file). Tipayamongkholgul et al. (2009) report that sea level pressure is a constant predictor of dengue incidence and outbreaks in the southern tropical coasts of Thailand.

In Asian Pacific countries, temperature is known to be associated with the recorded number of dengue cases (Andraud et al., 2013), its fluctuations significantly affect the Aedes vector population (Tran et al., 2013). Laboratory experiments show that adult $A$. aegypti start to die when the air temperature is above $40^{\circ} \mathrm{C}$ and their larvae perish when the water temperature surpasses $34^{\circ} \mathrm{C}$ (Christophers 1960). The negative association with the number of dengue cases and the number of rainy days, windspeed and sealevel pressure we found indicates that lesser strength of these variables influences mosquito vector survival and thus contribute to increased dengue incidence. Also according to our study, the relative humidity was observed to be highest during the monsoon (recording about 164 cases per 100,000 inhabitants as shown in the Supplementary file); and when relative humidity is higher than $85 \%$, mosquitoes may not survive longer to spread the dengue virus. This suggests that very high relative humidity is a predictor of diminishing dengue incidence in the Gulf of Thailand similarly reported by Wongkoon et al. (Wongkoon et al., 2016b). However, in certain parts of the world, such as central Europe, blood searching activities of some mosquito spp. were recorded at a relative humidity as high as $92 \%$ (Petric, 1989).

The seasonal average cloud cover has a significant positive effect on the reported dengue cases, as, for every unit increase in the monthly average cloud cover, dengue incidence seemed to increase by a value of 0.04 . In southern tropical coastal provinces such as Nakhon Si Thammarat, sea-level pressure seems to be a constant predictor for dengue epidemics (Tipayamongkholgul et al., 2009). However, one cannot say that these correlations imply causality as other socio-demographic factors may also be at play. While climatic factors may in part explain dengue cases, it is far from being the only driver as there are probably socio-economic drivers or non-environmental factors such as movement of people, urbanization and population density that play a bigger role in dengue infection outbreaks in the province. Particularly, the seasonal climate phenomena especially during the rainy seasons of Nakhonsi Thammarat drives dengue transmission. In our study, districts with the highest population were shown to be dengue hotspots over the years (Figure 9). This influence is supported by other authors (Schmidt et al., 2011; Ho et al., 2018). However, Pak Phanang, the fifth most densely populated district in Nakhon Si Thammarat, is surprisingly a coldspot for dengue incidence.

Planning prevention and treatment activities before the dengue season are quite difficult as the number and location of cases vary dramatically from year to year. The random distribution statistically significant spatial clusters of dengue cases found in our study mean that dengue infection in the province is not restricted to a particular region but that any district is at risk regardless of the year. On the one hand, negative Z-score values at high confidence levels in several districts, as well as positive Z-scores in many other districts, show both low and high values in the dataset were more randomly clustered than would be expected.

\section{Strengths and limitations}

This is the first study that investigates geographical patterns of dengue fever at the district level for a period of 17 years in the southern region of Thailand. The findings provide evidence that dengue hotspot districts are randomly spread across the province 
with epidemics occurring every two to three years. Also, it provides evidence of spatial dimension indicating the need to include socio-economic and lifestyle determinants in choosing effective dengue control measures. Dengue is an increasingly worrisome public health problem and requires interventions tailored at the grassroots level in every district. There are also limitations in our study, we focused on reported dengue cases, so the data represent only confirmed cases. The usually low level of reporting, poor disease surveillance, low case fatality rate and inconsistent comparative analyses make the true incidence and impact of dengue likely to be significantly higher than that currently reported. Still, the information gained is sufficient to support the degree of association between environmental variables and dengue incidence discovered. Although this does not necessarily mean that one causes the other, we can state that some environmental factors can affect dengue incidence.

Environmental variables such as temperature, relative humidity, rainfall, number of rainy days, wind speed and evaporation describe a region's climate and their values are obtained by querying GIS databases. This makes it subject to uncertainties as these obtained values are estimates of the true spatial climate or predictions thereof. Also, one cannot rule out the fact that spatial structures of some regions could be consistently underestimated or overestimated as the case may be.

\section{Conclusions and policy implication}

Countries across South-East Asia will continue to depend on agriculture and specific plantations for the foreseeable future, a situation the requires the threat of certain areas becoming hotspots for mosquito-borne disease to be eliminated. Hence, there is a need to further investigate the role of the climate and the socio-environmental stress that supports dengue transmission, especially at the district level. This study provides public health information on statistically significant dengue incidence hotspots using existing health data and GIS tools supporting proficient resource allocation and effective decision-making to curb dengue infection and resource allocation.

\section{References}

Andraud M, Hens N, Beutels P, 2013. A simple periodic-forced model for dengue fitted to incidence data in Singapore. Math Biosci. 244:22-8.

Benedum CM, Seidahmed OM, Eltahir EA, Markuzon N, 2018. Statistical modeling of the effect of rainfall flushing on dengue transmission in Singapore. PLoS Negl Trop Dis 12:e0006935.

Braks M, Van Ginkel R, Wint W, Sedda L, Sprong H, 2014. Climate change and public health policy: translating the science. Int J Environ Res Public Health 11:13-29.

Brownstein JS, Rosen H, Purdy D, Miller JR, Merlino M, Mostashari F, Fish D, 2002. Spatial analysis of West Nile virus: rapid risk assessment of an introduced vector-borne zoonosis. Vector Borne Zoonotic Dis 2:157-164.

Bureau of Epidemiology, 2019. BOE National Disease Surveillance website. Bureau of Epidemiology (BOE), Ministry of Public Health (MOPH), Thailand. Available from: http://www.boe.moph.go.th/boedb/surdata/disease.php?ds=66
Accessed: 12 September 2019.

Christophers S, 1960. Aëdes aegyptì (L.) the yellow fever mosquito; its life history, bionomics and structure. Cambridge University Press, New York, 1960. xii+ 739 pp. Illus.

Chumpu R, Khamsemanan N, Nattee C, 2019. The association between dengue incidences and provincial-level weather variables in Thailand from 2001 to 2014. PLos One 14:e0226945.

CityPopulation. 2019. Thailand: major cities, towns \& communes. Available from: http://citypopulation.de/Thailand-Cities.html Accessed: 7 October 2019.

Clark DV, Mammen Jr MP, Nisalak A, Puthimethee V, Endy TP, 2005. Economic impact of dengue fever/dengue hemorrhagic fever in Thailand at the family and population levels. Am J Trop Med Hyg 72:786-91.

Cuong HQ, Hien NT, Duong TN, Phong TV, Cam NN, Farrar J, Nam VS, Thai KT, Horby P, 2011. Quantifying the emergence of dengue in Hanoi, Vietnam: 1998-2009. PLoS Negl Trop Dis 5:e1322.

Department of Disease Control, 2001. Case definition for surveillance. Factsheet (in Thai). Available from: http://203.157.15.4/surdata_Accessed: 17 September 2019.

Department Provincial Administration, 2019. Official statistics registration systems Thailand: Registration statistics system. Department Provincial Administration. Available from: http:/stat.bora.dopa.go.th/stat/statnew/statTDD/views/showDi strictData.php? rcode $=80 \&$ statType $=1 \&$ year $=61$ Accessed: 02 August 2019.

Depradine C, Lovell E, 2004. Climatological variables and the incidence of Dengue fever in Barbados. Int J Environ Health Res 14:429-41.

Edwards H, 1982. Ion concentration and activity in the haemolymph of Aedes aegypti larvae. J Exp Biol 101:143-51.

Ehelepola N, Ariyaratne K, Buddhadasa W, Ratnayake S, Wickramasinghe M, 2015. A study of the correlation between dengue and weather in Kandy City, Sri Lanka (2003-2012) and lessons learned. Infect Dis Poverty 4:42.

ESRI, 2021. How Hot Spot Analysis (Getis-Ord Gi*) works. ESRI. Available from: https://pro.arcgis.com/en/pro-app/latest/toolreference/spatial-statistics/h-how-hot-spot-analysis-getis-ordgi-spatial-stati.htm Accessed: 2 January 2021.

Getis A, Ord JK. 2010. The analysis of spatial association by use of distance statistics. In: Perspectives on spatial data analysis. Springer, Berlin, Germany.

Githeko AK, Lindsay SW, Confalonieri UE, Patz JA, 2000. Climate change and vector-borne diseases: a regional analysis. Bull WHO 78:1136-47.

Gubler DJ, 2002. Epidemic dengue/dengue hemorrhagic fever as a public health, social and economic problem in the 21 st century. Trends Microbiol 10:100-3.

Gubler DJ, Reiter P, Ebi KL, Yap W, Nasci R, Patz JA, 2001. Climate variability and change in the United States: potential impacts on vector-and rodent-borne diseases. Environ Health Perspect 109:223-33.

Guha-Sapir D, Schimmer B, 2005. Dengue fever: new paradigms for a changing epidemiology. Emerg Themes Epidemiol 2:1.

Ho CC, Ting C-Y, Raja DB, 2018. Using public open data to predict dengue epidemic: assessment of weather variability, population density, and land use as predictor variables for dengue outbreak prediction using support vector machine. Indian J Sci. Technol 11:1-8.

Jeefoo P, Tripathi NK, Souris M, 2011. Spatio-temporal diffusion 
pattern and hotspot detection of dengue in Chachoengsao province, Thailand. Int J Environ Res Public Health 8:51-74.

Jetten TH, Focks DA, 1997. Potential changes in the distribution of dengue transmission under climate warming. Am J Trop Med Hyg 57:285-97.

Lawless JF, 1987. Negative binomial and mixed Poisson regression. Canad J Stat 209-25.

Meteorological Department of Thailand, 2015. The climate of Thailand. Meteorological Department of Thailand. Available from: https://www.tmd.go.th/en/archive/thailand_climate.pdf Accessed: 20 October 2019.

Ministry of Public Health, 2019. Annual epidemiological surveillance report. War Veterans Organization, Bangkok (19962005) (in Thai). Department of Disease Control, Ministry of Public Health, Bangkok.

Mondini A, Chiaravalloti-Neto F, 2008. Spatial correlation of incidence of dengue with socioeconomic, demographic and environmental variables in a Brazilian city. Sci Total Environ 393:241-8.

Ongart C, Pojaman S, Orathai S, Sirisamphan B, 2017. Applied epidemiology for prevention and control of D.H.F. Ministry of Public Health, National Library of Thailand Cataloging in Publication Data.

Ord JK, Getis A, 1995. Local spatial autocorrelation statistics: distributional issues and an application. Geogr Anal 27:286-306.

Osei FB, Duker AA, 2008. Spatial and demographic patterns of cholera in Ashanti region-Ghana. Int J Health Geogr 7:44.

Pachauri RK, Allen MR, Barros VR, Broome J, Cramer W, Christ R, Church JA, Clarke L, Dahe Q, Dasgupta P, 2014. Climate Change 2014: Synthesis Report. Contribution of Working Groups I, II and III to the Fifth Assessment Report of the Intergovernmental Panel on Climate Change / R. Pachauri and L. Meyer (editors), Geneva, Switzerland, IPCC, 151 p., ISBN: 978-92-9169-143-2 . Available from 10013/epic.45156.d001

Paily K, Chandhiran K, Vanamail P, Kumar NP, Jambulingam P, 2013. Efficacy of a mermithid nematode Romanomermis iyengari (Welch)(Nematoda: Mermithidae) in controlling tree holebreeding mosquito Aedes albopictus (Skuse)(Diptera: Culicidae) in a rubber plantation area of Kerala, India. Parasitol Res 112:1299-304.

Petric D, 1989. Seasonal and daily mosquito (Diptera, Culicidae) activity in Vojvodina. University of Novi Sad, Faculty of Agriculture, Novi Sad, Serbia.

Provincial Office, 2021. Geography of Nakhonsi Thammarat Province. Ministry of Labour, Nakhonsi Thammarat. Available from: https://nakhonsithammarat.mol.go.th/en/overall/ geography Accessed: 05 February 2021.

Ramasamy R, Surendran SN, 2011. Possible impact of rising sea levels on vector-borne infectious diseases. BMC Infect Dis 11:1-6.

Reid C, 2000. Implications of climate change on malaria in Karnataka, India. Brown University, Providence, RI, USA.

Rotela C, Fouque F, Lamfri M, Sabatier P, Introini V, Zaidenberg M, Scavuzzo C, 2007. Space-time analysis of the dengue spreading dynamics in the 2004 Tartagal outbreak, Northern Argentina. Acta Trop 103:1-13.

Sánchez-Martín J-M, Rengifo-Gallego J-I, Blas-Morato R, 2019. Hot spot analysis versus cluster and outlier analysis: An enquiry into the grouping of rural accommodation in Extremadura (Spain). ISPRS Int J Geoinf 8:176.

Schmidt W-P, Suzuki M, Thiem VD, White RG, Tsuzuki A,
Yoshida L-M, Yanai H, Haque U, Anh DD, Ariyoshi K, 2011. Population density, water supply, and the risk of dengue fever in Vietnam: cohort study and spatial analysis. PLoS Med 8:e1001082.

Shepard DS, Undurraga EA, Halasa YA, 2013. Economic and disease burden of dengue in Southeast Asia. PLoS Negl Trop Dis 7:e2055.

Si Y, Debba P, Skidmore A, Toxopeus A, Li L, 2008. Spatial and temporal patterns of global H5N1 outbreaks. The International Archives of the Photogrammetry, Remote Sensing and Spatial Information Sciences. Vol. XXXVII, pp 69-74. http://hdl.handle.net/10204/2758

Stewart-Ibarra AM, Lowe R, 2013. Climate and non-climate drivers of dengue epidemics in southern coastal Ecuador. Am J Trop Med Hyg 88:971-81.

Sulekan A, Suhaila J, Wahid NAA, 2021. Assessing the effect of climate factors on dengue incidence via a generalized linear model. Open J Appl Sci 10:549.

Tangena J-AA, Thammavong P, Wilson AL, Brey PT, Lindsay SW, 2016. Risk and control of mosquito-borne diseases in Southeast Asian rubber plantations. Trends Parasitol 32:402-15.

Thailand Health Ministry, 2001. The outlook for dengue fever in 2001 was higher than that of 2000. Communicable Disease Control Department. Ministry of Public Health, Thailand. RYT9. Available from: https://www.ryt9.com/s/prg/259907 Accessed: 26 April 2021.

Thailand Interior Ministry, 2016. Department of Lands. Lands Department. Available from: https://www.dol.go.th/Pages/ internet.aspx Accessed: 8 January 2021.

Thaivbd, 2019. Thailand vectorborne diseases. Thaivbd Thailand, Ministry of Public Health, MOPH. Available from: http://www.thaivbd.org/n/

Thammapalo S, Chongsuwiwatwong V, Geater A, Lim A, Choomalee K, 2005. Socio-demographic and environmental factors associated with Aedes breeding places in Phuket, Thailand. Southeast Asian J Trop Med Public Health 36:426-33.

Thammapalo S, Wonghiranrat W, Moonmek S, Sriplong W, 2011. Biting time of Aedes albopictus in the rubber plantation and the orchard, the southern-most of Thailand. J Vector Borne Dis 6:2.

Tian H, Huang S, Zhou S, Bi P, Yang Z, Li X, Chen L, Cazelles B, Yang J, Luo L, 2016. Surface water areas significantly impacted 2014 dengue outbreaks in Guangzhou, China. Environ Res 150:299-305.

Tian H, Zhou S, Dong L, Van Boeckel TP, Cui Y, Newman SH, Takekawa JY, Prosser DJ, Xiao X, Wu Y, 2015. Avian influenza H5N1 viral and bird migration networks in Asia. Proc Natl Acad Sci 112:172-7.

Tipayamongkholgul M, Fang C-T, Klinchan S, Liu C-M, King CC, 2009. Effects of the El Niño-Southern Oscillation on dengue epidemics in Thailand, 1996-2005. BMC Public Health 9:1-15.

Tran A, l'Ambert G, Lacour G, Benoît R, Demarchi M, Cros M, Cailly P, Aubry-Kientz M, Balenghien T, Ezanno P, 2013. A rainfall-and temperature-driven abundance model for Aedes albopictus populations. Int J Environ Res Public Health 10:1698-719.

Tsai P-J, Lin M-L, Chu C-M, Perng C-H, 2009. Spatial autocorrelation analysis of health care hotspots in Taiwan in 2006. BMC Public Health 9:1-13.

Victor T, Chandrasekaran B, Reuben R, 1994. Composite fish culture for mosquito control in rice fields in southern India. 
Southeast Asian J Trop Med Public Healthn 25:522-7.

WHO, 1997. Dengue haemorrhagic fever: diagnosis, treatment, prevention and control. World Health Organization, Geneva, Switzerland.

WHO, 2005. Using climate to predict infectious disease epidemics. World Health Organization, Geneva, Switzerland.

WHO, 2011. Comprehensive guideline for prevention and control of dengue and dengue haemorrhagic fever. World Health Organization, Geneva, Switzerland.

WHO, 2012. Global strategy for dengue prevention and control 2012-2020. World Health Organization, Geneva, Switzerland.

WHO, 2014. Dengue and severe dengue. World Health Organization. Regional Office for the Eastern Mediterranean, Geneva, Switzerland.

Wongkoon S, Jaroensutasinee M, Jaroensutasinee K, 2016a. Spatio-temporal climate-based model of dengue infection in Southern, Thailand. Trop Biomed 33:55-70.

Wongkoon S, Jaroensutasinee M, Jaroensutasinee K, 2016 b. Spatio-temporal climate-based model of dengue infection in Southern, Thailand. TropBiomed 33:55-70.

Wu N, Liao G, Li D, Luo Y, Zhong G, 1991. The advantages of mosquito biocontrol by stocking edible fish in rice paddies. Southeast Asian J Trop Med Public Health 22:436-42.

Wu P-C, Lay J-G, Guo H-R, Lin C-Y, Lung S-C, Su H-J, 2009. Higher temperature and urbanization affect the spatial patterns of dengue fever transmission in subtropical Taiwan. Sci Total Environ 407:2224-33.

Wu X, Lu Y, Zhou S, Chen L, Xu B, 2016. Impact of climate change on human infectious diseases: Empirical evidence and human adaptation. Environ Int 86:14-23.

Xiao J, Liu T, Lin H, Zhu G, Zeng W, Li X, Zhang B, Song T, Deng A, Zhang M, 2018. Weather variables and the El Nino Southern Oscillation may drive the epidemics of dengue in Guangdong Province, China. Sci Total Environ 624:926-34.

Xu Z, Bambrick H, Yakob L, Devine G, Lu J, Frentiu FD, Yang W, Williams G, Hu W, 2019. Spatiotemporal patterns and climatic drivers of severe dengue in Thailand. Sci Total Environ 656:889-901.

Yeshiwondim AK, Gopal S, Hailemariam AT, Dengela DO, Patel HP, 2009. Spatial analysis of malaria incidence at the village level in areas with unstable transmission in Ethiopia. Int $\mathrm{J}$ Health Geogr 8:1-11. 